\title{
L2-L3 Intervertebral Space
}

National Cancer Institute

\section{Source}

National Cancer Institute. L2-L3 Intervertebral Space. NCI Thesaurus. Code C112327.

The space between the $L 2$ and $L 3$ vertebrae. 